\title{
Renin, Endothelial NO Synthase and Endothelin Gene EXPRESSION IN THE 2KIDNEY-1CLIP GOLDBLATT MODEL OF LONG-TERM RENOVASCULAR HYPERTENSION
}

\author{
S. W. Reinhold ${ }^{1 *}$, D. C. Uihlein ${ }^{1 *}$, C. A. Böger ${ }^{1}$, S. Kloiber ${ }^{1}$, K. Frölich ${ }^{1}$, T. Bergler ${ }^{1}$, B. Banas ${ }^{1}$, \\ F. Schweda ${ }^{2}$, B. K. Krämer ${ }^{3}$ \\ ${ }^{1}$ Klinik und Poliklinik für Innere Medizin II, University of Regensburg, Regensburg, Germany, \\ ${ }^{2}$ Institut für Physiologie, University of Regensburg, Regensburg, Germany, \\ ${ }^{3}$ Marienhospital Herne, Ruhr-University Bochum, Germany
}

\begin{abstract}
Objective: Numerous reports have shown the influence of renin, nitric oxide (NO) and the endothelin (ET) systems for regulation of blood pressure and renal function. Furthermore, interactions between these peptides have been reported. Aim of our study was to investigate the relative contribution of these compounds in long-term renovascular hypertension / renal ischemia.

Methods: Hypertension / left-sided renal ischemia was induced using the $2 \mathrm{~K} 1 \mathrm{C}-$ Goldblatt rat model. Renal renin, ET-1, ET-3 and endothelial NO synthase (eNOS) gene expression was measured by means of RNAse protection assay at different timepoints up to 10 weeks after induction of renal artery stenosis.

Results: Plasma renin activity and renal renin gene expression in the left kidney were increased in the clipped animals while eNOS expression was unchanged. Furthermore, an increase in ET-1 expression and a decrease of ET-3 expression was detected in early stenosis.

Conclusions: While renin is obviously involved in regulation of blood pressure and renal function in unilateral renal artery stenosis, ET-1, ET-3 and endothelium derived NO do not appear to play an important role in renal adaptation processes in long-term renal artery stenosis, although ET-1 and ET-3 might be involved in short-term adaptation processes.
\end{abstract}

Key words: blood pressure, renin angiotensin system, nitric oxide, endothelins, long-term renal artery stenosis, RNAse protection assay

\section{INTRODUCTION}

The renin-angiotensin system (RAS) has generally been accepted to play an important role in blood pressure homeostasis. Renin forms angiotensin I from angiotensinogen and angiotensin $\mathrm{I}$ is thereafter trans-

\footnotetext{
* Both authors contributed equally to this paper.
}

formed by the angiotensin converting enzyme in the biologically active angiotensin II (AT-II). AT-II is known to be vasoconstrictive and stimulates the release of aldosterone, thereby causing sodium retention. The upregulation of renin in renal artery stenosis due to the activation of the renal baroreceptor is thought to cause renal hypertension by activating the renin-angiotensin system.

$\mathrm{NO}$ is known as vasorelaxing molecule. In the model of $2 \mathrm{~K} 1 \mathrm{C}$ renovascular hypertension $\mathrm{NO}$ has been proven to be involved in maintaining blood flow. $\mathrm{NO}$ is thought to act as a vasodilatator and thereby to antagonise the high levels of AT-II in both kidneys [1]. $\mathrm{NO}$ measurements have shown that endogenous $\mathrm{NO}$ production is increased in the contralateral kidney of 2K1C rats three weeks after clipping [2].

The ETs comprise a group of three 21-amino acid peptides, having vasoactive, inotropic and mitogenic properties [3]. ET-1 acts on vascular muscle cells causing a long-lasting vasoconstriction [4]. Short-term renal artery stenosis in the $2 \mathrm{~K} 1 \mathrm{C}$ model of renovascular hypertension has resulted in an upregulation of renal ET1 in the clipped kidney. ET-2 was not found in rat kidneys [5]. Furthermore ET-1 and ET-3 seem to be regulated in opposite ways as shown in a rat renal ischemia reperfusion model 6 hours after reperfusion [5].

In addition, many interactions between these above compounds have been found: NO for instance downregulates the ET-1 expression and AT-II is a known stimulator of ET-1 expression [6, 7].

Since the contribution of these different mediators in renovascular hypertension especially with regard to long-term regulation is unclear, the aim of our study was to investigate the effects of unilateral renal artery clipping, using the $2 \mathrm{~K} 1 \mathrm{C}$-model, on renal renin, eNOS, ET-1 and ET-3 gene expression.

\section{Methods}

All animal experiments were conducted according to the National Institutes of Health guidelines for the care and use of animals in research. 
80 male Wistar rats, weighing $150 \mathrm{~g}$, having free access to tap water and standard commercial pellet chow (Altromin C1000, Lage, Germany) were used. Unilateral renovascular clipping was induced in a total of 40 rats and a sham operation in 40 control rats. A stenosis of the left renal artery was induced by a $0.2 \mathrm{~mm}$ silver clip. Anaesthesia was done using methohexital (75 $\mathrm{mg} / \mathrm{kg}$ IP). 8 animals of each group were sacrificed 3 , $7,12,28$ and 70 days after surgery.

Systolic blood pressure was measured using the tail cuff method (process control blood pressure 209000; TSE, Homburg/Saar, Germany) [8]. Blood was collected for measurement of plasma renin activity after decapitation. The kidneys were immediately removed, weighed and frozen using liquid $\mathrm{N}_{2}$ and stored at $-80^{\circ} \mathrm{C}$.

Renal renin, eNOS, ET- 1 and -3 and $\beta$-actin gene expression from whole kidney was analysed using RNAse-protection assays as previously reported [9]. $\beta$-actin was used as housekeeping gene. Plasma renin activity was measured by a commercially available ANG-I-radioimmunoassay (Diasorin, Saluggia, Italy).

Results are expressed as mean \pm SEM. The Student's t-test was used for statistical analysis after testing for normal distribution. $\mathrm{P}$ values $<0.05$ were considered statistically significant.

\section{RESULTS}

\section{KIDNEY WEIGHT}

Kidney weight of the unclipped kidneys increased by time. It was significantly higher than the clipped kidneys starting at day 7. The contralateral (unclipped) kidney had a higher weight compared to the control group starting at day 28. The weight of the clipped kidneys was significantly lower than control starting at day 3 and did not change significantly over time (Fig. 1).

\section{BLOOD Pressure}

Systolic blood pressure significantly increased in the 2K1C-group to $162.5 \pm 8 \mathrm{mmHg}$ on day $1,179 \pm 11$ $\mathrm{mmHg}$ on day 2 and $189 \pm 7 \mathrm{mmHg}$ on day 20 after clipping, thereafter levelling off at slightly lower levels $(155 \pm 7 \mathrm{mmHg}$ at day 40 and $149 \pm 3 \mathrm{mmHg}$ at day 63). The control group presented significantly lower systolic blood pressure values at every postoperative timepoint (Fig. 2).

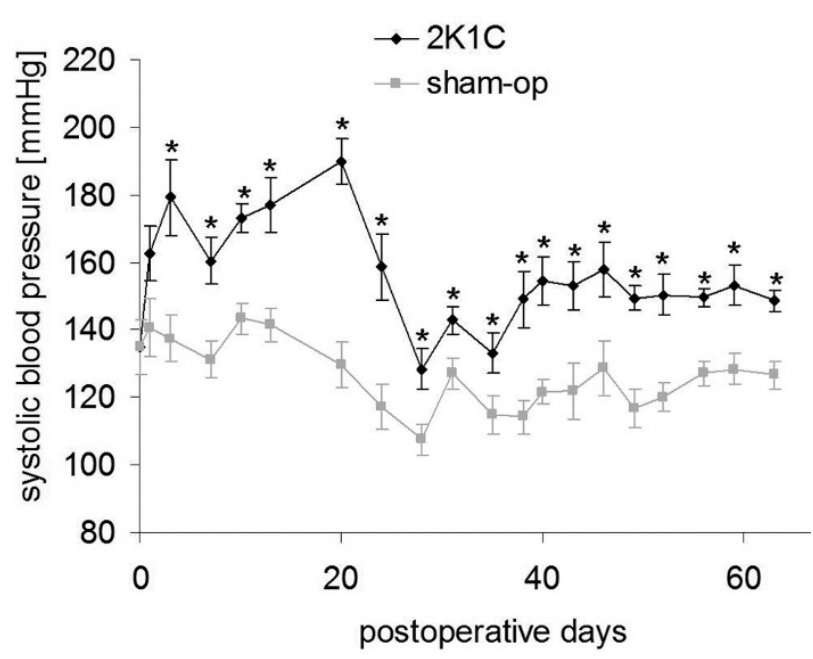

Fig. 2. Systolic blood pressure after clipping and sham-operation. Systolic blood pressure significantly increased in the 2K1C-group to $162.5 \pm 8 \mathrm{mmHg}$ on day $1,179 \pm 11 \mathrm{mmHg}$ on day 2 and $189 \pm 7 \mathrm{mmHg}$ on day 20 after clipping, thereafter levelling off at slightly lower levels $(155 \pm 7 \mathrm{mmHg}$ at day 40 and $149 \pm 3 \mathrm{mmHg}$ at day 63). The control group presented significantly lower systolic blood pressure values at every postoperative timepoint (significant vs. control *, $\mathrm{p}<0.05)$.

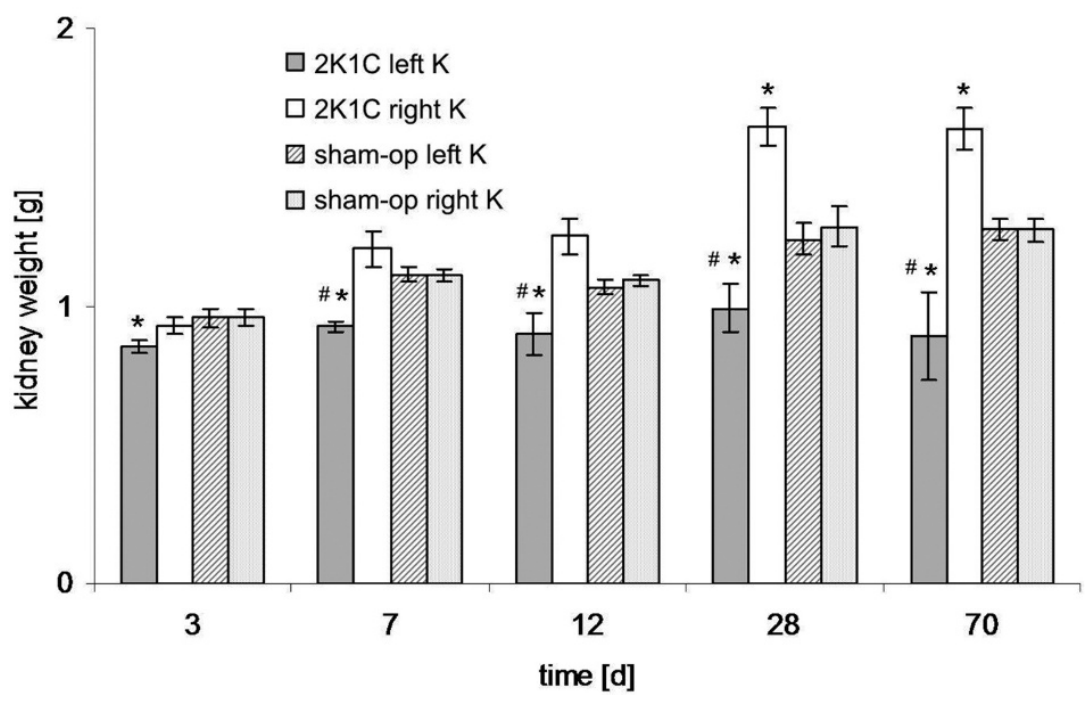

Fig. 1. Kidney weight in the $2 \mathrm{~K} 1 \mathrm{C}$ group and control group at different timepoints after surgery. Kidney weight of the unclipped kidneys increased by time. It was significantly higher compared to the clipped kidneys starting at day 7 . The contralateral (unclipped) kidney had a higher weight compared to the control group starting at day 28. The weight of the clipped kidneys was significantly lower than control starting at day 3 and did not change significantly over time (significant vs. control *; significant vs. contralateral side \#, $\mathrm{p}<0.05)$. 


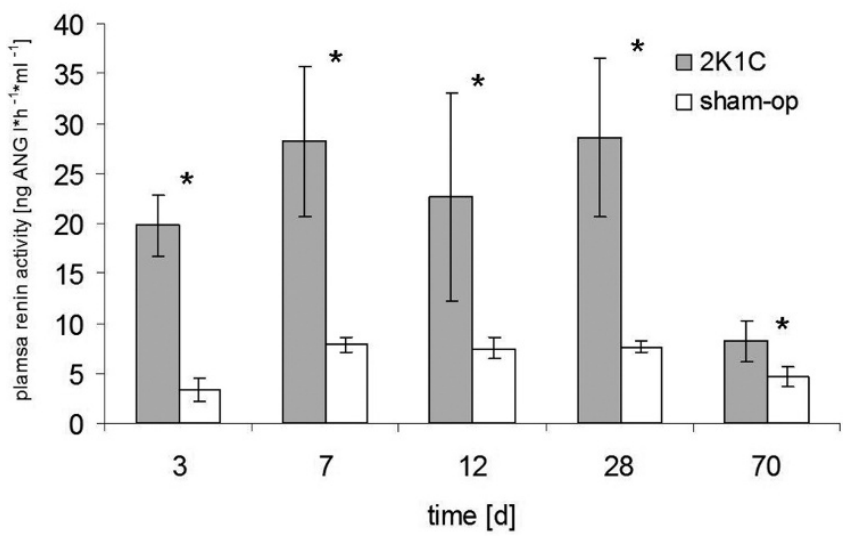

Fig. 3. Plasma renin activity in the clipped and unclipped group. Plasma renin activity in the $2 \mathrm{~K} 1 \mathrm{C}$-group was six times higher than in the control group at day 3. Plasma renin activity then decreased to about 3.5 fold on days 7,12 and 28 and to about 2 fold of control group on day 70 (significant vs. control $*, \mathrm{p}<0.05)$.

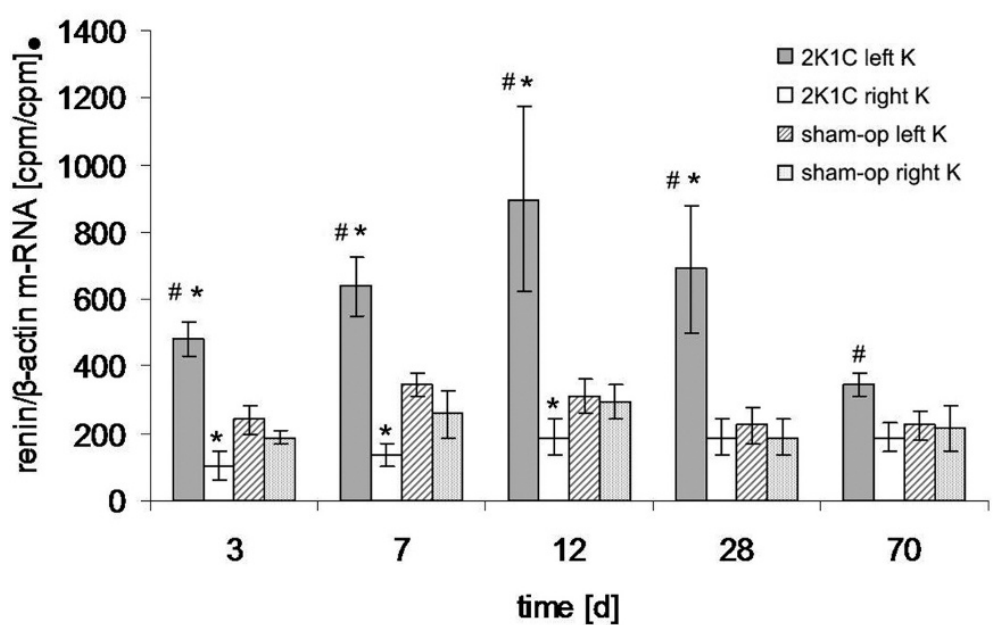

Fig. 4. Gene expression of renin in the clipped and unclipped kidneys $(\mathrm{K})$ at different timepoints after surgery. Renal renin gene expression was higher at all timepoints in the clipped kidney compared with the unclipped kidney and at day 3 to 28 compared to control, whereas the contralateral kidney displayed renin gene suppression to $\sim 50 \%$ of control at day 3 to 12 (significant vs. control *; significant vs. contralateral side \#, $\mathrm{p}<0.05)$.

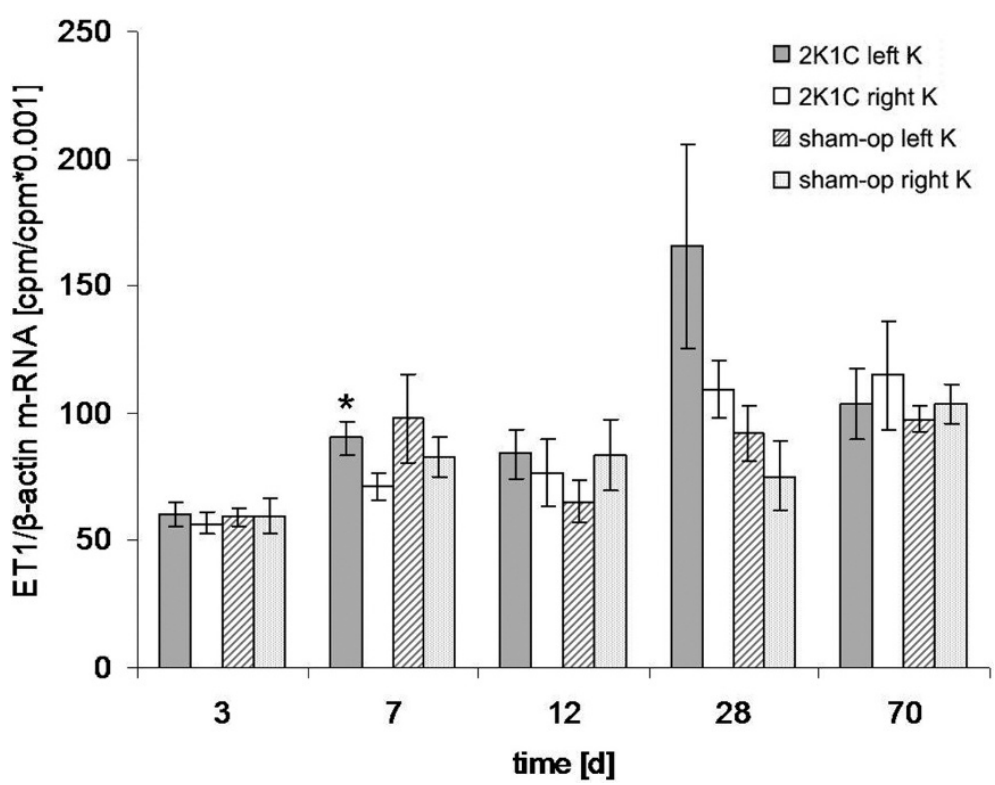

Fig. 5. Gene expression of ET-1 in the clipped and unclipped kidneys $(\mathrm{K})$ at different timepoints after surgery. ET-1 gene expression tended to increase with time in all groups and was significantly higher in the clipped kidney on day 7 compared with the contralateral kidney (significant vs. contralateral side *, $90.4 \pm 6.7$ vs. $71.2 \pm$ $5.5, \mathrm{p}<0.05)$.

\section{Plasma Renin Activity}

Plasma renin activity in the $2 \mathrm{~K} 1 \mathrm{C}$-group was six times higher than in the control group at day 3. Plasma renin activity then decreased to $\sim 3.5$ fold on days 7,12 and 28 and to $\sim 2$ fold of control group on day 70 (Fig. 3).

\section{RENIN GENE Expression}

Renal renin gene expression was higher at all timepoints in the clipped kidney compared with the un- clipped kidney and at day 3 to 28 compared to control, whereas the right contralateral kidney displayed renin gene suppression to $\sim 50 \%$ of control at day 3 to 12 (Fig. 4).

\section{Renal ET-1 Gene Expression}

ET-1 tended to increase with time in all groups. Furthermore ET-1 gene expression in the clipped kidney was higher on day 7 compared with the contralateral kidney $(90.4 \pm 6.7$ vs. $71.2 \pm 5.5 ; \mathrm{p}=0.046)$ (Fig. 5). 


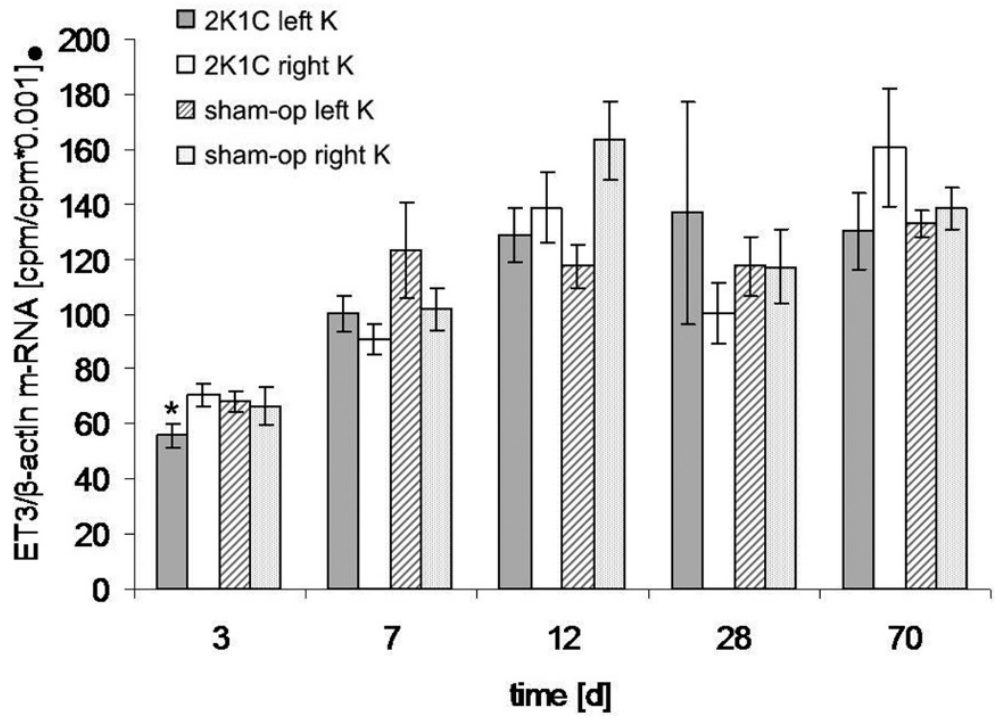

Fig. 6. Gene expression of ET-3 in the clipped and unclipped kidneys $(\mathrm{K})$ at different timepoints after surgery. ET-3 gene expression was significantly lower in the clipped kidneys compared with the contralateral kidney at day 3 (significant vs. contralateral side $*, 55.7 \pm 7.7$ vs. $70.6 \pm 7.3, \mathrm{p}<0.05)$.
Renal ET-3 Gene Expression

ET-3 tended to increase with time in all groups. ET-3 gene expression was significantly lower in the clipped kidneys compared with the contralateral kidney at day 3 (55.7 \pm 7.7 vs. $70.6 \pm 7.3 ; \mathrm{p}=0.02)$ (Fig. 6).

\section{eNOS GENE EXPRESSION}

Renal eNOS gene expression 3 days after clipping was $255.5 \pm 17.0$ in the clipped kidney vs. $229.3 \pm 20.9$ in the contralateral kidney. On day 7 eNOS gene expression was $135.3 \pm 12.6$ vs. $138.4 \pm 22.6$. On day 12 eNOS gene expression was $274.2 \pm 31.5$ vs. $275.9 \pm$ 23.7. On day 28 eNOS gene expression was $358.0 \pm$ 77.4 vs. $309.4 \pm 37.1$. On day 70 eNOS gene expression was $149.3 \pm 13.4$ vs. $200.7 \pm 48.5$.

All these changes did not reach statistical significance.

\section{Discussion}

The aim of our study was to determine - in contrast to most other published data that dealt with short-term effects - the long-term effects of experimental unilateral renal artery stenosis on blood pressure, kidney weight and renal renin, ETs and eNOS expression.

A significant increase in blood pressure after clipping is well known in $2 \mathrm{~K} 1 \mathrm{C}$-rats $[2,10]$, making them a commonly used model of renovascular hypertension. Our data fits with other findings showing a lower, but still increased blood pressure four weeks after clipping [1]. Furthermore, many authors also show an increase in weight of the contralateral kidney while the weight of the clipped kidney decreased with time [11, $12,13]$. In contrast some authors found no change in the weight of the clipped kidney, while they also found an increase in the contralateral kidney [14, 15]. Shamoperated rats showed as expected no difference in kidney weight $[16,17]$.

Our findings of appropriate changes in kidney weight and blood pressure after unilateral clipping suggest effective creation of unilateral renal artery stenosis. The apparent decrease in measured systolic blood pressure on day 20 is thought to be due to a change in cuff size for blood pressure measurement with growth of rats.

Renal hypoperfusion is well-known as a stimulator of both renal renin gene expression and plasma renin activity. Several groups including ourselves have shown an increased plasma renin activity and increased ipsilateral renal renin gene expression after induction of unilateral renal artery stenosis [18]. Renin upregulation has generally been accepted as neurohumoral counterregulation in renal hypoperfusion to maintain post-stenotic renal perfusion and renal function.

In accordance to our findings many groups report decreasing, but still elevated plasma renin levels in the more chronic phase of renovascular hypertension [19, $20,21]$, as well as of increased renin RNA-levels in the clipped kidney and suppressed levels in the contralateral kidney in the early phase of $2 \mathrm{~K} 1 \mathrm{C}$-hypertension $[14,16,20]$.

We demonstrated that renal renin gene expression is upregulated in the clipped kidney as an early and long-term adaption process to renal hypoperfusion. In parallel downregulation of the renin gene expression occurs in the unclipped kidney most presumably due to systemic hypertension again as an early- and longterm adaption process. Hypertension most probably is due to an early markedly increased plasma renin activity that declines by time but still is inadequately high when related to systemic blood pressure, and presumably goes along with sodium retention in addition to vasoconstriction.

Short-term renal hypoperfusion has resulted in an upregulation of renal ET-1 and a downregulation of renal ET-3 [22]. Studies in patients with angioplasty of renal artery stenosis showed inconsistent results. While one report found no change of plasma ET-1 levels after repair, another report described an increased level of ET-1 [23, 24]. In a further study no difference in plasma ET-1 levels six weeks after experimental 2K1C-clipping compared to baseline were found [10]. However, since endothelins are known to act mainly in an autocrine/paracrine manner, plasma levels of endothelin-1 may not be sufficient to judge 
whether the endothelin system is involved i.e. in the pathophysiology of unilateral renal artery stenosis. An additional paper showed that the ET-system seemed to be activated in low-renin, volume-dependent $1 \mathrm{~K} 1 \mathrm{C}$ Goldblatt rats [25], however this model differs in several aspects to the $2 \mathrm{~K} 1 \mathrm{C}$ model, used by us.

Our findings that there is no difference in the gene expression of ET-1 and ET-3 at day 28 and 70 suggest, that ETs might not to be involved in long-term adaptation processes. In contrast ET-1 gene expression being upregulated in the clipped kidney on day 7 and endothelin-3 being downregulated on day 3, suggest, that ETs might be involved in short-term adaptation processes right after renal hypoperfusion.

Focusing on overall renal eNOS gene expression we found no significant difference at any timepoint. This matches well with previous findings that there is no difference at any timepoint in eNOS protein expression in the left and right kidneys of $2 \mathrm{~K} 1 \mathrm{C}$ rats when the clip was removed after 6 weeks and eNOS protein expression was measured before and after unclipping [26]. This study [26] reported in addition that there are different expression patterns in medulla (down-regulation) and cortex (up-regulation), which obviously could not be detected by us when analysing whole kidney eNOS gene expression.

The analysis of eNOS expression data in eNOS and nNOS deficient mice suggests that eNOS derived NO enhances renal renin gene expression [27]. Barton found that renal hypoperfusion leads to a stimulation of renal eNOS gene expression [28]. When using pharmacological NO donors as sodium nitroprusside renin secretion is increased [29]. According to our results, overall eNOS gene expression seems not to be quantitatively involved in adaption processes of whole 2K1C-rat-kidneys, though recent data show clearly a protective role for $\mathrm{NO}$ in $2 \mathrm{~K} 1 \mathrm{C}$ hypertensive mice [30].

Since angiotensin II has been reported to stimulate the release of endothelin-1 [29, 31], unilateral renal artery stenosis with resulting upregulation of the renin system might result in an increased expression of endothelins. Furthermore the endothelin-system has an inhibitory influence on renin [32]. This fits with our findings of the upregulation of endothelin-1 while the renin activity is high in early stenosis and decreasing renin levels after activation of the endothelin-system. Although there is clear evidence for interactions between renin and the ET-system, ETs appear not to be involved in chronic long term adaptation processes after unilateral renal clipping as discussed above.

Overall, the gene expression analysis of vasoactive mediators like the ETs and eNOS in whole kidney is a limitation of this study with regard to their differential expression and regulation in cortex and medulla [26, 33].

In conclusion, we demonstrated that the $2 \mathrm{~K} 1 \mathrm{C}$ model in male rats leads to a long-term stimulation of the renin system with ipsilateral upregulation and contralateral downregulation. ETs and endothelium derived NO seem to play no major role in chronic adaptation processes in the kidney of $2 \mathrm{~K} 1 \mathrm{C}$-rats, although ET-1 and ET-3 might be involved in short-term adaptation processes, but their functional relevance should be confirmed in further studies, using pharmacological agonists/antagonists and/or genetic knockout models.

\section{REFERENCES}

1. Sigmon DH, Beierwaltes WH: Influence of nitric oxide in the chronic phase of two-kidney, one clip renovascular hypertension. Hypertension 1998; 31: 649-56.

2. Turkstra E, Boer P, Braam B, Koomans HA: Increased availability of nitric oxide leads to enhanced nitric oxide dependency of tubuloglomerular feedback in the contralateral kidney of rats with 2-kidney, 1-clip Goldblatt hypertension. Hypertension 1999; 34: 679-84.

3. Evans JJ, Youssef AH, Yandle TG, Lewis LK, Nicholls MG: Endothelin-1 directly modulates its own secretion: studies utilising the cell immunoblot technique. Regul Pept 2003; 113: 149-53.

4. Zollmann FS, Paul M: Transgenic models for the study of endothelin function in the cardiovascular system. J Cardiovasc Pharmacol 2000; 35: S13-6

5. Firth JD, Ratcliffe PJ: Organ distribution of the three rat endothelin messenger RNAs and the effects of ischemia on renal gene expression. J Clin Invest 1992; 90: 102331.

6. Gupta A, Sharma AC: Despite minimal hemodynamic alterations endotoxemia modulates NOS and p38-MAPK phosphorylation via metallopeptidases. Mol Cell Biochem 2004; 265: 47-56.

7. Gray MO, Long CS, Kalinyak JE, Li HT, Karliner JS: Angiotensin II stimulates cardiac myocyte hypertrophy via paracrine release of TGF-beta 1 and endothelin-1 from fibroblasts. Cardiovasc Res 1998; 40: 352-63.

8. Schricker K, Holmer S, Krämer BK, Riegger G, Kurtz A: Control of renin gene expression in 2 kidney-1 clip rats. Kidney Int 1994; 46: 1539-41.

9. Hiyoshi H, Yayama K, Takano M, Okamoto H: Angiotensin type 2 receptor-mediated phosphorylation of eNOS in the aortas of mice with 2-kidney, 1-clip hypertension. Hypertension 2005; 45: 967-73.

10. Wang DS, Xie HH, Shen FM, Cai GJ, Su DF: Blood pressure variability, cardiac baroreflex sensitivity and organ damage in experimentally hypertensive rats. Clin Exp Pharmacol Physiol 2005; 32: 545-52.

11. Holmer S, Eckardt KU, Aedtner O, LeHir M, Schricker K, Hamann M, Götz K, Riegger G, Moll W, Kurtz A: Which factor mediates reno-renal control of renin gene expression? J Hypertens 1993; 11: 1011-9.

12. Leenen FH, de Jong W, de Wied D: Renal venous and peripheral plasma renin activity in renal hypertension in the rat. Am J Physiol 1973; 225: 1513-8.

13. Lou YK, Liu DT, Whitworth JA, Morris BJ: Renin mRNA, quantified by polymerase chain reaction, in renal hypertensive rat tissues. Hypertension 1995; 26: 6564.

14. Mai M, Hilgers KF, Wagner J, Mann JF, Geiger H: Expression of angiotensin-converting enzyme in renovascular hypertensive rat kidney. Hypertension 1995; 25: 674-8.

15. Sadjadi J, Puttaparthi K, Welborn MB 3rd, Rogers TE, Moe O, Clagett GP, Turnage RH, Levi M, Modrall JG: Upregulation of autocrine-paracrine renin-angiotensin systems in chronic renovascular hypertension. J Vasc Surg 2002; 36: 386-92.

16. Michel JB, Dussaule JC, Choudat L, Auzan C, Nochy D, Corvol P, Menard J: Effects of antihypertensive treatment in one-clip, two kidney hypertension in rats. Kidney Int 1986; 29: 1011-20.

17. Okuniewski R, Davis EA, Jarrott B, Widdop RE: A comparison of the development of renal hypertension in male and female rats. Clin Sci (Lond) 1998; 95: 445-51. 
18. Schricker K, Scholz H, Hamann M, Clozel M, Krämer BK, Kurtz A: Role of endogenous endothelins in the renin system of normal and two-kidney, one clip rats. Hypertension 1995; 25: 1025-9.

19. Morishita R, Higaki J, Nagano M, Mikami H, Ogihara T, Tanaka T, Ishii K, Okunishi $\mathrm{H}$, Miyazaki M: Consistent activation of prorenin mRNA in renal hypertensive rats. Can J Physiol Pharmacol 1991; 69: 1364-6.

20. Morton JJ, Wallace EC: The importance of the renin-angiotensin system in the development and maintenance of hypertension in the two-kidney one-clip hypertensive rat. Clin Sci (Lond) 1983; 64: 359-70.

21. Sawamura T, Nakada T: Role of dopamine in the striatum, renin-angiotensin system and renal sympathetic nerve on the development of two-kidney, one-clip Goldblatt hypertension. J Urol 1996; 155: 1108-11.

22. Ritthaler T, Göpfert T, Firth JD, Ratcliffe PJ, Krämer BK, Kurtz A: Influence of hypoxia on hepatic and renal endothelin gene expression. Pflugers Arch 1996; 431: 587-93.

23. Morganti A, Marana I, Airoldi F, Alberti C, Nador B, Palatresi S: Plasma endothelin levels: a meaningless number? J Cardiovasc Pharmacol 2000; 35: S21-23.

24. Teunissen KE, Postma CT, van Jaarsveld BC, Derkx FH, Thien T: Endothelin and active renin levels in essential hypertension and hypertension with renal artery stenosis before and after percutaneous transluminal renal angioplasty. J Hypertens 1997; 15: 1791-96.

25. Sventek P, Turgeon A, García R, Schiffrin EL: Vascular and cardiac overexpression of endothelin-1 gene in onekidney, one clip Goldblatt hypertensive rats but only in the late phase of two-kidney one clip Goldblatt hypertension. J Hypertens 1996; 14: 57-64.

26. Wickman A, Andersson IJ, Jia J, Hedin L, Bergstroem G: Endothelial nitric oxide synthase protein is reduced in the renal medulla of two-kidney, one-clip hypertensive rats. J Hypertens 2001; 19: 1665-73.

27. Wagner C, Gödecke A, Ford M, Schnermann J, Schrader J, Kurtz A: Regulation of renin gene expression in kidneys of eNOS- and nNOS-deficient mice. Pflugers Arch 2000; 439: 567-72.
28. Barton $\mathrm{CH}$, Ni Z, Vaziri ND: Effect of severe aortic banding above the renal arteries on nitric oxide synthase isotype expression. Kidney Int 2001; 59: 654-61.

29. Kurtz A, Götz KH, Hamann M, Kieninger M, Wagner C: Stimulation of renin secretion by NO donors is related to the cAMP pathway. Am J Physiol 1998; 274: F709-17.

30. Cervenka L, Vanecková I, Husková Z, Vanourková Z, Erbanová M, Thumová M, Skaroupková P, Opocensky M, Maly J, Chábová VC, Tesar V, Bürgelová M, Viklicky O, Teplan V, Zelízko M, Kramer HJ, Navar LG: Pivotal role of angiotensin II receptor subtype 1A in the development of two-kidney, one-clip hypertension: study in angiotensin II receptor subtype $1 \mathrm{~A}$ knockout mice. J Hypertens 2008; 26 (7): 1379-89.

31. Scholz H, Kurtz A: Involvement of endothelium-derived relaxing factor in the pressure control of renin secretion from isolated perfused kidney. J Clin Invest 1993; 91: 1088-94.

32. Kammerl MC, Grimm D, Kromer EP, Jabusch HC, Reif R, Morhard S, Endemann D, Fischereder M, Riegger GA, Krämer BK: Effects of aortic stenosis on renal renin, angiotensin receptor, endothelin and NOS gene expression in rats. Am J Nephrol 2002; 22: 84-9.

33. Abassi Z, Gurbanov K, Rubinstein I, Better OS, Hoffman A, Winaver J: Regulation of intrarenal blood flow in experimental heart failure: role of endothelin and nitric oxide. Am J Physiol 1998; 274: F766-74

Received: April 8, 2009 / Accepted: November 4, 2009

Address for correspondence:

Dr. Stephan W. Reinhold

Klinik und Poliklinik für Innere Medizin II - Nephrologie

Franz-Josef-Strauß-Allee 11

93053 Regensburg

Germany

Tel.: $\quad+499419447301$

Fax: $\quad+499419447302$

E-mail: stephan.reinhold@klinik.uni-regensburg.de 